\title{
UN EJEMPLO DE CORPORATIVISMO ESTADOUNIDENSE: LA CREACIÓN DE HOLLYWOOD
}

\section{AN EXAMPLE OF AMERICAN CORPORATISM: CREATING HOLLYWOOD}

\section{AUTORA}

Graciela Padilla Castillo: Becaria FPU. Departamento de Periodismo III, Facultad de Ciencias de la Información, Universidad Complutense de Madrid. gracielapadilla@ccinf.ucm.es

\section{CURRÍCULUM VITAE}

Doctoranda en Ciencias de la Información, en el programa con Mención de Calidad "Planteamientos teóricos, estructurales y éticos de la comunicación de masas", del departamento de Periodismo III (Teoría General de la Información), Facultad de Ciencias de la Información, Universidad Complutense de Madrid. Becaria FPU del Ministerio de Educación y Ciencia. Licenciada en Periodismo y Comunicación Audiovisual (2006), con Premio Fin de Carrera. Sus líneas de investigación se centran en Ficción televisiva, Teoría de la Información, Análisis Transaccional y Estudios de Género. Miembro del grupo de investigación consolidado UCM nº 94820.

\section{RESUMEN}

Este artículo analiza diversas fuentes históricas para repasar los comienzos de Hollywood y los primeros años del cine. Se basa en las ideas sobre el corporativismo norteamericano del profesor e investigador mexicano, D. José Luis Orozco. Con ello, y ese análisis de los primeros años, descubrimos que el trabajo, la producción, la 
distribución y el marketing del cine norteamericano actual no son, en absoluto, un fenómeno reciente.

\title{
PALABRAS CLAVE
}

Hollywood - Historia del Cine - Corporativismo - Star system.

\begin{abstract}
This article analyzes various historical sources to review the early days of Hollywood and the early years of cinema. It is based on the ideas about American corporatism by the Mexican professor and researcher, José Luis Orozco. With this, and that analysis of the early years, we discover that the work, production, distribution and marketing of American cinema today are not at all a recent phenomenon.
\end{abstract}

\section{KEY WORDS}

Hollywood - Film History - Corporatism - Star system.

\section{ÍNDICE}

1. Introducción.

2. Un ejemplo de corporativismo estadounidense: la creación de Hollywood.

3. En un suburbio del lejano Oeste.

4. Forma de trabajo en la gran industria del cine: el sistema de estudios.

5. La distribución y exhibición: cómo llegar al gran público.

6. Creación de estrellas. El star system.

7. El resultado: la película, ¿producto u obra de arte? 
8. De ayer a hoy. La historia siempre se repite.

9. Conclusiones.

10. Bibliografía.

\section{Introducción.}

El cine estadounidense ha llegado a todo el mundo sin dejar ningún espacio por conquistar. Incluso, la India ha inventado un sistema paralelo a Hollywood bajo el revelador nombre de Bollywood. Tienen su propio mercado y debido al gran número de población propia, ni siquiera necesitan exportarlo. Han hecho suyo el sistema de trabajo de la meca del cine y producen más películas que sus homónimos americanos.

Hace unos meses, las grandes marcas de cosmética occidental desembarcaron en China y Japón. El maquillaje de las geishas no está de moda entre el público de a pie, que ahora utiliza productos de Maybeline London, Maxfactor, Mac o Bobbie Brown, antes exclusivamente yanquis. Las jóvenes de ojos rasgados no sabían qué era un eyeliner o una barra de labios color rosa chicle. El cine les ha enseñado qué colores se llevan y las adolescentes orientales quieren parecerse a jóvenes estrellas norteamericanas como Scarlett Johansson, Kirsten Dunst, Lindsay Lohan, Mischa Barton o Sienna Miller. Todo es fruto de "la magia del cine".

En España, se han estrenado recientemente las dos películas más taquilleras de la historia hasta ahora: Spiderman 3 y Piratas del Caribe 3: en el fin del mundo. Así lo afirman todos los medios de comunicación. Sin embargo, ese sobrenombre es algo efímero. Serán las más taquilleras sólo hasta que aparezca la cuarta entrega de alguna de ellas o Hollywood invente una nueva trilogía. Los taquillazos abundan. Por lo 
menos, llega uno a nuestros cines cada mes. Personas de todas las edades y clases sociales llenan las salas en cada sesión. Muchos aún se sorprenden e intentan descifrar la fórmula de éxito. Es más simple de lo que parece: Estados Unidos ha aplicado su corporativismo y política de concentración al cine desde los primeros tiempos.

Ya en 1898, el gran espectáculo de la imagen atraía a las masas. Comenzó como espectáculo de barraca de feria. Pronto fascinó a todos los que se asomaban ante la gran pantalla. Por ello, es interesante y necesario estudiar cómo un arte tan sencillo como el cine se ha convertido en la gran industria que ha sido y es hoy. El éxito no es fruto del azar, sino del trabajo y la planificación más exhaustiva. El cine no puede ser una excepción. Por ello, sigue triunfando. Los profesionales del medio saben repetir las fórmulas de éxito en cada nueva película:

“Una obra cinematográfica es el resultado del trabajo planificador y directivo de gran número de elementos artísticos, técnicos, organizadores y económicos; sólo puede salir bien cuando su producción esté inspirada por un espíritu de estrecha colaboración entre esos elementos" (Dadek, 1962, p. $61)$.

Esta definición tan reveladora demuestra que, detrás del aspecto artístico, hay todo un engranaje económico y profesional en el que no pensamos al ver una película. Sin embargo, el cine no es sólo arte gratuito y altruista. Busca beneficios, desde la escritura del guión hasta el lanzamiento en DVD. El proceso pretende la amortización del presupuesto invertido y la generación de los máximos beneficios posibles en tres pasos principales, definidos por Walter Dadek (1962, p. 17): “La economía cinematográfica se edifica sobre tres ramas: producción, distribución y exhibición, correspondiéndose la distribución con el comercio al por mayor de las demás ramas económicas, y la exhibición con el comercio al por menor." 
El resultado de esta cadena de trabajo son miles de millones de dólares cada fin de semana, con cada estreno cinematográfico. La fábrica de sueños funciona mejor cada día. No lo percibimos conscientemente. Los espectadores preferimos quedarnos sólo con la película. Sin embargo, hay que pensar en aquellos pioneros que inventaron un aparto mágico, al principio fantasmagórico. El proyector de cine refleja sobre la pantalla nuestros sueños, nuestras aventuras favoritas, nuestras peores pesadillas o las vidas que quisimos vivir alguna vez. Los estudios saben cómo tocar la fibra sensible del público y lo hacen con cada entrega de su trabajo, desde la primera proyección en una café de París, a manos de los hermanos Lumiére, o en un teatro de Hollywood. La fórmula funcionó de la forma más simple, sin que nadie redactara un manual o un protocolo:

“Nadie inventó de forma deliberada el Sistema de Estudios de Hollywood. Los métodos de producción utilizados anteriormente no eran de inferior calidad ni más primitivos. El sistema de Hollywood permitía minimizar los costes de producción y, al mismo tiempo, hacer con regularidad aquellas películas que parecían reportar los mayores beneficios. Adolph Zukor fue el que abrió el camino en este sentido, y sin él, Hollywood hubieses sido probablemente algo muy distinto" (Gomery et al, 1998, p. 81).

Por todo ello, merece la pena estudiar los comienzos del Séptimo Arte, su funcionamiento, sus porqués, sus intereses y política interna; en definitiva, las claves de un éxito creciente y siempre actual. El cine es el triunfo del corporativismo estadounidense, esta vez, en el arte. 


\section{Un ejemplo de corporativismo estadounidense: la creación de}

\section{Hollywood.}

Todos los grandes libros de Historia del Cine parten del tiempo de los Pioneros, apelativo que se utiliza para referirse a los inventores del Séptimo Arte. No obstante, para conocer los comienzos del cine como gran espectáculo de masas y fenómeno industrial, hay que adelantarse casi una década para llegar al Hollywood de los primeros años del siglo XX.

En aquellos años, toda la actividad se concentraba en la Costa Este de Estados Unidos. Hasta allí habían llegado el invento francés de los hermanos Lumiére y los demás prototipos de otras ciudades europeas. Como sigue ocurriendo ahora, el país supo apropiarse sabiamente de inventos extranjeros para mejorarlos y hacerlos propios. Esa política llevó a que Nueva York fuera rápidamente un lugar propicio para producir, rodar y exhibir películas.

Uno de los artífices de aquel milagro fue el inventor Thomas Edison. Suele ser recordado por desarrollar el teléfono. Aunque lo cierto es que aportó mucho más en el mundo cinematográfico, con variadas y múltiples patentes que abarcaban todo el proceso productivo de la película:

“Thomas A. Edison (1847-1931) ha pasado a la historia como autor de más de mil patentes, entre ellas el fonógrafo (1877), la lámpara eléctrica incandescente (1879), la película de celuloide perforado (1889) y, a comienzos de la última década del siglo XIX, el kinetógrafo y el kinetoscopio, luego reconvertido en vitascopio. Edison y su empresa, Edison Manufacturing Company, estuvieron en permanente litigio para monopolizar la industria del cine. Denunció - y obtuvo sentencias favorables - a quienes no usaban sus cámaras y proyectores y exigía un 
canon por ello. El conflicto había de resolverse con un acuerdo del que Edison quería excluir a las productoras rivales más importantes, American Mutoscope y Biograph Company. Sin embargo, éstas desataron una campaña de prensa para desprestigiar a Edison. Las disputas se saldaron con una solución negociada: la creación de la MPPP (Motion Picture Patents Company) en 1908 por parte de Edison, Kalem, Kleine, Lubin, Biograph, Selig y Vitagraph, además del fabricante East Kodak - que aseguraba un acuerdo de que no proveería de película a ningún otro - y de las francesas Pathé Frères y Méliès" (Sánchez Noriega, 2006, p. 198).

El historiador y profesor de la Universidad Complutense de Madrid, también dedica al monopolio de Edison algunas líneas en su libro sobre los anales de Hollywood, que ayudan a completar la descripción anterior:

"Hasta ese momento, existía un mercado libre en los tres sectores básicos. La MPCC, conocida como el Trust, es el monopolio que integra todos los sectores de la industria del cine desde 1909 a 1915: fabricación de película virgen, de cámaras y aparatos proyectores, y la producción, distribución y exhibición de películas. Este monopolio, creado a semejanza del existente en el sector eléctrico, practicó todo tipo de acciones legales y amenazas para evitar la competencia, impidiendo la importación de material, fijando precios altos y exigiendo porcentajes por la utilización de sus patentes, que poseía todas y, por tanto, estaba en condiciones de monopolizar el mercado: sólo circulaban películas de la MPCC, que otorgaba licencias a los distribuidores seleccionados por ella, llegando a un acuerdo con los exhibidores para poner películas propias en proyectores patentados por ellos y exigiendo un canon semanal. De ese modo eliminaban toda competencia, incluida la importancia de películas extranjeras, salvo las de Pathé y Méliès" (Sánchez Noriega, 2006, p. 198). 
Con esta compleja máquina empresarial, Edison copó el mercado cinematográfico. Abarcaba todas las etapas del proceso de producción, distribución y exhibición de la película. No había sitio para la más mínima competencia. Se alió con todos los profesionales del nuevo medio, americanos y extranjeros. Además, contaba con la tecnología, una baza importante para fundar cualquier monopolio. Lo que no sabía el inventor es que el cine sería un invento tan grandioso y atraería a tanta gente, que sus competidores no querían quedarse al margen. Banqueros, hombres del teatro, de la música y del espectáculo, sentían que existía mercado para todos. Había que llevar el cine a la población de todo el país y un pequeño grupo de elegidos no era suficiente desde el aspecto de visto logístico y económico. Mucho dinero en juego; demasiado para que les tocara la lotería sólo a unos pocos afortunados.

Comenzó la lucha entre los colosos y los bien llamados pequeños independientes. La disputa fue cruenta. La compañía de Edison era demandada en muchas ocasiones y solía emerger airosa de los juicios, como era de esperar. El gran Goliat del Séptimo Arte parecía un gigante imbatible. La única posibilidad era escapar, espacial y geográficamente, de sus garras. Así lo explican Gomery et al (1998, p. 79):

"La génesis de Hollywood cabe buscarla en el fracaso de la Motion Picture Patents Company a la hora de monopolizar la industria cinematográfica. Dicho trust tuvo dificultades para mantener el control de ésta. Como ha ocurrido con tantos monopolios anteriores o posteriores, los competidores trataron hábilmente de escapar a su dominio. En tan sólo seis años (19091914), productores independientes como Carl Laemmle, Marcus Loew y William Fox se opusieron al Trust y contribuyeron a crear Hollywood".

Es el tiempo de la segunda hornada de pioneros. En esta ocasión, no son inventores de máquinas o proyectores, sino auténticos aventureros, expedicionarios que cruzaron 
el árido territorio centroamericano para irse a la otra costa. Los que no conocemos aquel lugar, imaginamos la Costa Oeste simplemente como el lugar del cine, lleno de estudios y autopistas. Tomamos los retratos que nos ofrecen las películas. Pero esta perspectiva imaginaria nada tiene que ver con el Hollywood de la época a la que nos referimos. En aquellos años, la Costa Este era desierto, territorio inhóspito. Sólo tenía una ventaja: estaba tan lejos de Nueva York que a nadie le preocupaba qué harían, allá a lo lejos, unos pocos locos. Muertos de hambre, sed y calor, volverían a pedir amparo a los pocos meses. Lo que no sabían los hombres de Edison es que el futuro estaba precisamente en aquel territorio lejano e incómodo a primera vista. La competencia se iba lejos y eso le ayudaría a hacerse más grande, con menos inconvenientes. Nadie les vigilaba y la semilla germinó, aunque empezaron desde cero, debido al famoso Trust:

"La guerra de patentes iniciada con violencia furibunda por Edison, concluyó, como todas las guerras, con la firma de un acuerdo. Las artimañas de los abogados de Edison y las negociaciones entre bastidores condujeron a un pacto entre las grandes compañías productoras, que fue firmado tras un opíparo banquete, en el que los comensales, entre brindis y sonrisas, se conjuraron para no permitir que nadie pudiera disfrutar de las migajas económicas de aquel festín cinematográfico. Así nacía un poderoso cartel internacional, la M.P.P.C. (Motion Pictures Patents Company), que bajo la jefatura de Edison agrupaba a la Biograph, la Vitagraph, la Essanay, al coronel Selig, a Sigmund Lubin, a la Kalem, al distribuidor George Kleine y a los productores franceses Pathé y Méliès. El objetivo de este trust regido por Edison era el de imponer una disciplina - disciplina de monopolio, entiéndase - en el anárquico mercado cinematográfico. Los productores asociados debían pagar anualmente a Edison un impuesto de medio centavo por cada pie de película impresionada, cada distribuidor debía proveerse de una licencia anual que costaba 5.000 dólares y cada exhibidor debía cotizar 
dos dólares semanales. Quien no cumpliera estas drásticas imposiciones corría el riesgo de ser perseguido judicialmente por utilizar aparatos cuyas patentes pertenecian al trust" (Gubern, 1997, pp. 77-78).

Edison era "el dictador de la industria americana del celuloide" (Gubern, 1997, p. 78), en el país que se definía como adalid de la democracia, la igualdad y las oportunidades. Como siempre, todo dictador tiene sus detractores y los de Edison tenían nombres: Zukor, Laemmle y Fox. El historiador Román Gubern se refiere al primero en estos términos:

“Adolph Zukor (1873-1975) es el independiente que más hizo por el sistema de Hollywood. Comenzó con la compañia Famous Players in Famous Plays, cuyo nombre revela la importancia del guión y de las estrellas, con la que llevó al cine obras de teatro exitosas interpretadas por actores de fama, como Elizabeth, reina de Inglaterra (La reine Elizabeth, Louis Mercantor, 1912), protagonizada por Sarah Bernhardt" (Sánchez Noriega, 2006, p. 199).

La descripción anterior lleva a reflexionar sobre un tema que se tratará ampliamente más adelante: Edison no había contado con los actores. No sabía que las películas se venderían gracias a las estrellas que participaban en ellas. Lo desconocía, básicamente, porque no procedía del mundo del teatro. En cambio, Zukor sí tenía experiencia en este campo y se le ocurrió vender las películas de otra forma. Inventó el star system. Antes de ello, hay que recordar a sus compañeros de aventuras, como Laemmle, que también pensó en los actores:

“Judio alemán de nacimiento, Carl Laemmle (1867-1939) comenzó con un pequeño cine para pasar a la distribución y producción. Funda la Independent Motion Picture y contrata a una de las primeras estrellas de la Historia del Cine, Florence Lawrence, y a la más emblemática del silente, 
Mary Pickford. En 1915 crea la Universal con sus famosos estudios de Hollywood, que eran visitados por los turistas, consiguiendo así ingresos atípicos" (Sánchez Noriega, 2006, p. 199).

Es curioso comprobar que ese trío de independientes fundó pequeños estudios que hoy son los mayores del mundo. El tercero en ser citado será William Fox, cuyo apellido remite directamente al otro gran estudio que faltaba por citar:

"Piratería para unos y avatares de la libre competencia para otros, la guerra del celuloide conoció los episodios más pintorescos. Pero la batalla de los Independientes no se planteó con toda agresividad hasta que William Fox, apoyado en algunas amistades políticas influyentes de Nueva York, llevó en 1913 ante los tribunales de la M.P.P.C., acusándola de violar la Ley Sherman contra los monopolios, que data de 1890 y que es conocida t6ambién con el nombre de ley antitrust. El pleito fue largo y la sentencia condenatoria contra el trust no se pronunció hasta 1917. Pero sin esperar el fallo judicial, los Independientes siguieron luchando contra el trust, lanzando películas que introducían el sistema europeo de nombres famosos y obras costosas para atraer al gran público" (Gubern, 1997, pp. 78-79).

Las posibilidades para los Independientes parecían mínimas, pero no se dejaron intimidar. Rodaban con su propio material, en lugares escondidos y lejos de los ojos de los espías de Edison, que eran muchos. Román Gubern lo describe así antes de pasar al relato de la fundación de Hollywood en el lejano estado de California:

"Los Independientes eran gentes dispuestas a jugarse el tipo para defender sus negocios de exhibición. Algunos, perseguidos por Edison, tuvieron que abandonar la batalla y salir disparados hacia Cuba o México. Pero la mayoría plantaron cara al trust con mil tretas y argucias. Por esta razón, los 
Independientes fueron pasando de la exhibición a la producción de películas, que rodaban ocultos en graneros, garajes o almacenes abandonados, como si fuesen delincuentes, valiéndose de cámaras tomavistas importadas de otros países, desafiando así los tentáculos de la vasta y poderosa organización de Edison, con sus detectives privados, sus sagaces picapleitos y los fulminantes mandamientos judiciales que paralizaban los rodajes clandestinos, confiscaban sus aparatos y permitían el arresto de productores, técnicos y artistas" (Gubern, 1997, p. 78).

\section{En un suburbio del lejano Oeste.}

Sólo hay que imaginar, por un momento, la situación descrita por Gubern para entender por qué se hizo necesario desplazarse tan lejos. No había espacio para la creación y la clandestinidad ahogaba, poco a poco, la imaginación de los Independientes. Tenían que buscar subterfugios continuamente y su trabajo no podía tener la calidad que buscaban. Hacía falta un iniciador, un hombre de talento que osaría a mudarse muy lejos. Ese individuo fue D. W. Griffith. Pasaría a la historia por sus grandes películas (Intolerancia, El nacimiento de una nación). Aunque pocos saben que él fue uno de los primeros en huir hacia Los Ángeles:

"Griffith contribuyó a trasladar a las costas californianas el centro de gravedad del cine norteamericano, anteriormente repartido entre Nueva York y Chicago. Durante el invierno de 1910, su compañía emigró a Los Ángeles y allí volvió en cada nueva temporada mala. La Biograph fue imitada por numerosas firmas; la fundación de Hollywood fue, no obstante, obra de los Independientes y no del Trust" (Sadoul, 1998, p. 96).

Otras teorías prefieren no citar a ningún pionero en particular, ya que no se sabe con exactitud quién pudo ser el primero en llevarse la cámara al hombro. Por ello, 
también se dice que se eligió California por casualidad. La meca del cine se estableció allí porque en el Este hacía frío. La climatología permitía pocos rodajes en exteriores y obligaba a tener estudios y fabricar grandes decorados. El Oeste, en cambio, ofrecía un sol casi perpetuo durante todo el año y precipitaciones mínimas. Román Gubern (1997, p. 81) también cita esta hipótesis:

"Algunos de ellos comenzaron a alejarse de las grandes ciudades del Este para buscar refugio en las regiones menos pobladas del Oeste. El productor que inauguró esta ruta fue el llamado coronel Selig, antiguo tapicero de Chicago y especialista en westerns, que en busca de clima apropiado se desplazó a Los Ángeles para rodar los exteriores de El conde de Montecristo (The count of Monte Cristo, 1907), de Francis Boggs, al tiempo que se alejaba discretamente del cuartel general de Edison (aunque más tarde se asoció al trust). El lugar elegido por Selig reunía condiciones óptimas para el rodaje de exteriores: variedad de paisajes y un cielo luminoso casi todo el año. Además, la proximidad de la frontera de México ofrecía una protección inmejorable contra la incursión de los detectives neoyorquinos".

Selig fue el primero. Las buenas experiencias se transmiten rápido y otros que buscaban una excusa para huir, la encontraron en el acierto de aquel hombre. Le imitaron otros productores, "que se fueron cobijando en los suburbios de Los Ángeles, especialmente en uno llamado Hollywood, antiguo feudo de los indios cahuenga y cherokee y así bautizado por la esposa de un granjero de Michigan asentado alli en 1857. Hollywood significa, literalmente, bosque de acebos. En aquel tranquilo lugar, con resonancias épicas muy próximas, entre las aguas del Pacífico y los picos de San Gabriel, iba a alzarse la más fabulosa fábrica de mitos que el hombre hubiera podido soñar" Gubern (1997, p. 81).

Resulta curioso pensar en esos orígenes. La tierra en la que se establecieron era un lugar inmundo. No había servicios de electricidad o agua corriente. No existían 
carreteras, sino unos pocos caminos desérticos. Tampoco había viviendas y mucho menos, fábricas o estudios para crear nada. Hollywood se hizo desde cero y curiosamente, robándole terreno a los indios. Incluso su nombre es fruto de la casualidad, porque llamaron Hollywoodland a aquella montaña y no sería Hollywood plenamente hasta que un huracán se llevara las cuatro últimas letras. Pero eso ocurrirá años más adelante y hay que volver a los primeros tiempos, a la mudanza épica de un extremo a otro del país:

"La historia de la formación de Hollywood recuerda, en bastantes aspectos, la epopeya de la colonización del Oeste. Ciudad creada ex novo por la afluencia de aventureros, como Dodge City, Dallas, Wichita o Abilene, adquirió pronto esa bronca reputación de las ciudades Far-West en su época heroica. En un Hollywood asolado por las rivalidades de los Independientes encontraremos a personajes tan inesperados como León Trotski, que actúa de oscuro figurante en varias películas - como El clarín de la paz (The battle cry of peace, 1916) de Blackton - y hasta aparece junto a la estrella Clara Kimball Young en Mi esposa oficial (My oficial wife, 1916) de James Young" (Gubert, 1997, p. 82).

La semilla brotó a pesar de ser plantada en territorio árido. Nueva York quedaba muy lejos y había espacio para la creación. Estos pioneros sabían lo que hacían. Provenían del mundo del espectáculo y veían el cine como una extensión de lo anterior, un nuevo apéndice que podía hacerse grande, ya que además resultaba más barato que el teatro.

Hollywood ofrecía algo diferente: películas que entretenían a todos los públicos, un divertimento barato al alcance de todos. No requería grandes inversiones y las películas empezaron a multiplicarse. Había muchas ilusiones, aventuras y sueños que el respetable deseaba ver: "Ya hacía tiempo que los teatros ofrecían una sola obra en 
sesiones que duraban dos o más horas. Los largometrajes habrían de seguir el mismo modelo. Los noticiarios de corta duración y las películas de animación serían un complemento, pero el punto fuerte lo constituirían los largometrajes. Esto trajo consigo la necesidad de que las películas contaran historias de un interés extraordinario y que su coste fuera mucho más elevado que antes" (Gomery et al, 1998, p. 57).

Mientras tanto, Nueva York fue perdiendo autoridad. El corporativismo en la Costa Oeste era macizo y hercúleo. El odio hacia el monopolio les había hecho más fuertes y el trust acabó desapareciendo porque su corporativismo no era libre, sino de obligado cumplimiento:

“Con la desaparición del Motion Picture Patents Trust, los independientes de Hollywood buscaron el modo de afianzar, controlar e incluso dominar el negocio de la producción cinematográfica. Durante los años 10, las compañias que habian alcanzado el éxito, encabezadas por la Famous Players-Larsky, desarrollaron un sistema para la producción de largometrajes de carácter popular. Este método industrial habría de conocerse como el sistema de producción de Hollywood. Sobre la base de los largometrajes, del star system y del Sistema de Estudios, las compañías de Hollywood mostraron al mundo el modo de hacer películas económicamente rentables" (Gomery et al, 1998, p. 57).

\section{Forma de trabajo en la gran industria del cine: el sistema de estudios.}

El éxito por casualidad no puede durar mucho tiempo y los Independientes de Hollywood lo sabían. Por ello, crearon un sistema de trabajo eficaz que les permitiera rodar el mayor número de películas en el menor tiempo posible, tratando todo tipo de argumentos. Era el Sistema de Estudios. En el cine sólo trabajarían 
profesionales especializados en un área muy concreta y la correcta interrelación con sus compañeros llevaría a que los rodajes fueran cortos. Cada minuto se aprovechaba al máximo, porque cada uno tenía una función muy definida, como los obreros de una máquina de montaje. No había herramientas, ni martillos, ni tuercas, sino un guión que era hecho realidad, desde que el estudio lo aprobaba:

"La Famous Players-Lasky estableció el sistema de trabajo de los estudios, sistema que incluía un jefe de estudio, un realizador y una secretaria de rodaje. Una vez que Adolph Zukor y Jesse Lasky aprobaban un proyecto, el primero asignaba las naves disponibles para la filmación y el personal necesario para hacer el guión, los decorados y el vestuario. Cada estudio contaba con todas aquellas personas cuyos servicios pudieran necesitarse durante el rodaje de una película, desde un cuerpo propio de policía para contener a las multitudes, hasta retenes de bomberos dispuestos a entrar en acción cuando se incendiaban los decorados de madera. A principios de los años 20, los estudios de cine, que se extendían a lo largo de varias hectáreas, funcionaban como verdaderas ciudades en los suburbios de Los Ángeles" (Gomery et al, 1998, p. 63).

Zukor y Lasky no eran los únicos pioneros en el sistema hollywoodiense. Thomas H. Ince fundó, en 1913, los estudios Inceville. Era otro hombre de gran inteligencia para los negocios y tuvo la genial idea de aplicar el sistema de trabajo de la industria automovilística Ford a su estudio. Como el cine era algo nuevo, no había manuales a seguir. Sin embargo, Ince pensó que el éxito de la fabricación de coches podría trasladarse a la fabricación de películas. Al fin y al cabo, en ambos procesos se buscaba un producto fácil de fabricar en serie, casi sin diferenciación entre los ejemplares para ganar tiempo y dinero. Debía hacerse con rapidez y ánimo para agradar a todo el mundo. Coches y películas no estaban tan lejos como parecían: 
"A partir de esa fecha se extiende los que se ha llamado el sistema de estudios. El estudio está encabezado por una jerarquía bifronte: la cúpula directiva que, desde Nueva York, define las líneas de producción, establece los presupuestos y organiza la distribución y exhibición; y el equipo de producción de Hollywood, que pone en marcha los planes de realización de películas de acuerdo con las directrices neoyorquinas. En este sistema, los directivos estudian un guión y aprueban la realización del filme, dejando libertad al productor para desarrollar el proyecto ateniéndose al guión. Cada equipo de trabajo, con miembros especializados en las distintas profesiones del cine, rueda en sus estudios su película simultáneamente a las de otros" (Sánchez Noriega, 2006, p. 210).

Como en los coches, no todas las películas serían iguales. La idea original de Ford fue fabricar todos los modelos con la misma forma y sólo en color negro. Con el tiempo, la industria automovilística iría ampliándose en formas y colores. El cine tomó la iniciativa antes, ya que las personas buscaban películas muy diferentes y los estudios se dieron cuenta de ello muy pronto. De hecho, Adolph Zukor fue más allá, ya que "clasificó las películas en tres categorías (A, B y C) en función de la fama y el sueldo de los actores que intervenían" (Sánchez Noriega, 2006, p. 210) Cada película tenía un precio y de las tres se podían obtener beneficios, porque gozaban de distintos públicos.

El trabajo era meticuloso, con un procedimiento simple pero efectivo, en el que cada uno conocía su papel dentro de la cadena. El personaje más importante era el secretario de rodaje, que vigilaba el cumplimiento de cada tarea. Estaba en todas partes, controlaba el trabajo del cámara y del peluquero, del foquista y del último actor secundario. El director sólo tenía que decir acción o corten, porque cuando se ponía a rodar, todo estaba dispuesto. 
El horario se fijaba por horas y minutos. Cada día de rodaje añadido podía costar miles de dólares no presupuestados, así que todo debía discurrir según el plan previsto. Además, después de una película se rodaba otra inmediatamente. Un retraso en un rodaje podía perjudicar a la película siguiente, y ésta a todas las que vinieran detrás. Los jefes de los estudios planeaban las películas que se iban a rodar durante todo el año, teniendo en cuenta la disponibilidad de espacio, actores y profesionales:

\begin{abstract}
"Se hacía un uso eficaz de los decorados, utilizándolos una y otra vez, y adaptándolos a los diferentes argumentos. Los directores artísticos se ocupaban de la construcción de los decorados, los directores de reparto tenían como misión elegir los artistas, los maquilladores perfeccionaban los tintes y disolventes con el fin de conseguir la estética cinematográfica más adecuada, y los cámaras rodaban los guiones tal y como estaban escritos, sin añadir ni quitar nada" (Gomery et al, 1998, p. 64).
\end{abstract}

Por encima de todos estos profesionales estaba el productor, un hombre muy importante dentro del estudio y casi siempre, olvidado por el público. No obstante, los premios Oscar de la Academia de Cine estadounidense nos recuerdan su importancia cada año. El Premio a la Mejor Película lo recoge el productor, en lugar del director. Él es quien se encarga de llevar a buen término la película. Ocurría así desde los inicios: "El productor se convertía en el amo de todos los elementos del éxito o del fracaso artístico. La preocupación del rendimiento lo dominaba: su consejo de administración evaluaba su valor en porcentaje de beneficios. Su guía fue exclusivamente la box office, la taquilla" (Sadoul, 1998, p. 189).

En este punto, hay que recordar que el cine pretendía conseguir beneficios por encima de todo, algo que hoy puede parecer una obviedad. Edison y su trust buscaban dinero al crear el monopolio. Y los aventureros de Hollywood también lo 
perseguían; en el Oeste no buscaban precisamente la mera realización artística. Buquet Corleto, especializado en el ámbito económico trata de explicar el sistema de trabajo en Hollywood con términos financieros:

"Todas las industrias culturales cuentan con estas características: sus funciones de producción tienen costes unitarios decrecientes, las economías de escala incentivan la concentración empresarial $y$, finalmente como resultado, todas las industrias culturales están dominadas por un pequeño grupo de empresas muy poderosas, polarizadas en el otro extremo con una infinidad de pequeñas empresas con un poder de mercado insignificante: majors e indies" (Buquet, 2005, p. 101).

Más adelante, el autor va más allá y explica cómo ese sistema ha llegado hasta nuestros días. La industria del cine se ha convertido en la segunda más fuerte del país:

"Las industrias culturales logran el segundo mayor superávit exportador de EE.UU. (el primero es el obtenido por la industria aeroespacial). La discusión ideológica, que parte de la realidad, se centra en la cuestión de si los bienes culturales deberían formar parte de la lista de productos con respecto a los que se defiende la abolición de las barreras al comercio o si, por el contrario, es lícito restringir el comercio de los bienes culturales (con cuotas, aranceles o impuestos) con el objetivo de proteger a los ciudadanos nacionales e incentivar la expresión creativa dentro de las industrias culturales nacionales" (Buquet, 2005, p. 272).

La afirmación es interesante. Aunque este análisis no pretende estudiar aspectos éticos. El trabajo de la industria de Hollywood funciona y sigue vigente porque el corporativismo en Estados Unidos no ha pasado de moda; esa es la parte que 
interesa. Hay que entender por qué triunfó el sistema de estudios, cómo una cadena de trabajo sencilla y bien planeada llevó al éxito y a la recogida de beneficios millonarios. Sólo habría un pequeño imprevisto en el camino: la televisión, derivado doméstico del cine. Cuando nació dicho aparato, en 1938, el Séptimo Arte sufrió trágicas consecuencias, como explica el historiador Sánchez Noriega (2006, p. 215):

\begin{abstract}
"El sistema de estudios, vigente durante más de tres décadas en el cine norteamericano, experimenta a lo largo de los años cincuenta una transformación radical debida fundamentalmente a tres factores interrelacionados: a) la pérdida de espectadores y la evolución del público; b) la expansión de la televisión; y c) la sentencia antimonopolio que impide a las productoras ser dueñas de las salas de exhibición".
\end{abstract}

A los grandes estudios se les ocurrió que podrían combatir contra la pequeña pantalla comprando emisoras locales. Los productores de cine querían producir programas de televisión y la Paramount tomó la iniciativa comprando el primer canal de televisión. Incluso, buscaron unir ambos medios, encontrar lugares comunes y en 1949, “un equipo de televisión grabó en directo programas en un estudio y transmitió la señal hasta el cine, incluso grabando a los propios espectadores, pero la experiencia no tuvo éxito" (Sánchez Noriega, 2006, p. 216).

El cine estaba condenado, para bien o para mal, a caminar solo y debía dejar que la televisión disfrutara de su propia andadura. Por ello, el Tribunal Supremo de Estados Unidos dictó una sentencia histórica. Obligaba a los estudios a dejar de adquirir emisoras de televisión. En adelante, los grandes estudios sólo podrían vender sus películas para que fueran emitidas en la pequeña pantalla.

Lo que parecía una obligación mal acogida y un impedimento para seguir creciendo, se convertiría en una nueva e importante línea de negocio; las cintas de segunda 
categoría ya tenían salida fuera de la gran pantalla: "Debido a que resulta más difícil imponer a los exhibidores las películas de serie B, los estudios transforman sus departamentos con el fin de producir series y películas específicas para televisión. Entre 1955 y 1960, la mayoría de los programas de máxima audiencia vienen de Hollywood" (Sánchez Noriega, 2006, p. 216). Hoy, basta con citar las series más vistas para comprobar que el cine salió ganando: House, Anatomía de Grey, CSI, Perdidos, Prison Break, Mujeres Desesperadas, Los Soprano, A dos metros bajo tierra, Alias o Sra. Presidenta han salido de los grandes estudios.

\section{La distribución y exhibición: cómo llegar al gran público.}

La producción y creación de una película, lejos de lo que se cree, no son los pasos más importantes. En la actualidad, se ha comprobado que una película extranjera puede ganar o perder el Oscar a la Película de habla no inglesa según sea su distribución en Estados Unidos. Si la productora y el director se interesan sobremanera y hacen llegar su película a un buen número de salas, podrán llevarse a casa la estatuilla dorada. El éxito está asegurado sólo si consigues que los críticos y un buen número de norteamericanos conozcan tu filme.

Ocurre lo mismo con las películas norteamericanas. Las productoras se pelean por distribuir el mayor número de copias posible y llegar a todas las salas de norte a sur. Hay que entender que el cine nació como un espectáculo de barraca, de feria ambulante, y este carácter de movilidad le persigue desde siempre. El proyector se llevaba de pueblo en pueblo, atrayendo a gentes muy diversas. Así lo relata Cuevas (1999, p. 252):

“En los comienzos del cine, cuando no existía más que el embrión de lo que más tarde habría de ser una importante industria, los propios productoresrealizadores de aquellas elementales partículas de los primeros tiempos 
basaban su negocio en las proyecciones ambulantes. La atención y favorable acogida prestada por el público a aquel extraño artilugio dio lugar a la necesidad de multiplicar los lugares de presentación, y por lo tanto a la obtención de un mayor número de duplicados sobre el original".

En el Hollywood de los primeros tiempos, continuó existiendo ese carácter nómada del cine. En un país tan grande, era importante llegar a ciudadanos de distintos territorios y ampliar mercado continuamente. Adolph Zukor, como buen visionario, se dio cuenta de ello. Entró en el medio como exhibidor en Nueva York, antes de ser productor con su compañía:

"La Famous Players-Lasky, al darse cuenta de que no todas las salas cinematográficas eran iguales, empezó a cobrarles más a los cines grandes, y menos a los situados en las poblaciones pequeñas, por el alquiler de sus películas. Los cines grandes pagaban entre quinientos y setecientos dólares semanales por las películas de cinco rollos, mientras que los pequeños pagaban en ocasiones menos de cincuenta. No obstante, los cines contrataban los productos que daban dinero, de modo que, de los 20.000 locales cinematográficos, aproximadamente, con que contaba Estados Unidos en 1919, una cuarta parte de ellos exhibía regularmente películas de la Famous Players-Lasky" (Gomery et al, 1998, p. 70).

Zukor aceleró su carrera en la exhibición gracias a los beneficios que obtenía. A mediados de 1921, la Paramount (antigua Famous Players-Lasky) ya era propietaria de 300 salas. Después, se fusionó con la cadena Balaban \& Katz: "En el plazo de seis años, la Paramount había dejado de ser un miembro secundario del mundo de la exhibición cinematográfica para convertirse en la empresa más importante del sector" (Gomery et al, 1998, p. 70). 
Ahí comenzaron a existir las grandes salas, los nickelodeons. Había que atraer a la gente en masa y se ganaba más dinero si se llenaban espacios más grandes: "La era de los cines modernos comenzó en 1914, cuando Samuel Roxy Rothapfel inauguró en Nueva York el Strand, un local con tres mil localidades. Roxy combinaba en sus salas las películas con las variedades" (Gomery et al, 1998, p. 71).

Los mismos autores creen que parte del éxito de las grandes salas se debe al lujo que existía en aquellos espacios mágicos. Ir al cine suponía toda una experiencia para el espectador, que se trasladaba a otro mundo ya antes de sentarse en su butaca:

"El estudio de arquitectura encabezado por los hermanos George y C. W. Rapp de Chicago diseñaban estos cines mezclando elementos procedentes de casi todas las épocas del pasado y del presente, incluidos elementos clásicos del arte francés y español, y del contemporáneo art déco. Los aficionados acudían al cine con la expectativa de toparse con un arco triunfal, una escalera monumental y un suntuoso vestíbulo forrado de columnas (inspirado en el Salón de los Espejos de Versalles)" (Gomery et al, 1998, p. 73).

Hoy, tenemos grandes salas modernas y eclécticas, de paredes lisas y oscuras, con altavoces invisibles. Sin embargo, la meca del cine vendía lujo y sueños. Los autores añaden que:

"Una vez dentro, los clientes pasaban por una serie de vestíbulos, antecámaras, corredores, salones, pasillos y salas. Los vestíbulos y salones eran, si cabe, más espectaculares que las fantasías arquitectónicas del exterior. Los acomodadores mantenían en todo momento una actitud digna y decorosa dentro de la sala donde tenía lugar el espectáculo. Guiaban a los clientes por el laberinto de salas y corredores, atendía a ancianos y niños, y 
subsanaban cualquier problema que pudiera presentarse. La compañía Balaban \& Katz los reclutaba entre los estudiantes de los colegios masculinos, los ataviaba con uniformes rojos, guantes blancos y hombreras amarillas, y les exigía que fueran serviciales y corteses hasta con los clientes más groseros. Todas las consultas que les dirigían los espectadores tenían que terminar con un gracias, y no estaba permitido aceptar propinas bajo ningún concepto" (Gomery et al, 1998, p. 75).

\section{Creación de estrellas. El star system.}

Para que la gente quisiera ir al cine no bastaba con llevarles a un lugar bonito, lujoso y cómodo. Necesitaban ver verosimilitud en las películas, identificarse con los actores para sentir lo que ellos simulan en la gran pantalla. De esa empatía surge la megalomanía. Los espectadores empiezan a amar a sus actores como si fueran auténticos ídolos religiosos. Y los señores de los estudios buscan rentabilidad en este amor incondicional e inexplicable:

"El estrellato es un fenómeno propio de la cultura de masas que tiene lugar, además de en el cine, en la televisión, la canción, la música, el deporte, la política, la moda, la religión, etc. La estrella cinematográfica es un doble fruto de la coincidencia de dos personalidades que se interrelacionan en un mismo sujeto, a quien ponen a su servicio: el actor y el personaje prototípico" (Sánchez Noriega, 2006, p. 219).

La gran pantalla convierte al actor en personaje, deja de ser persona para estar en un nivel de suprarrealidad, lejano al público. Las estrellas están en otro nivel porque Hollywood también fabrica estrellas. Precisamente, Sánchez Noriega (2006, p. 220) habla de los actores separando la realidad de la ilusión fabricada por la industria: 
"El actor es el profesional de la interpretación, el individuo que hace de la simulación y la adopción de identidades su trabajo, pero también alguien que posee una imagen pública en cuanto participa en fiestas, asiste a actos sociales, lleva una vida lujosa, se relaciona con personas importantes, etc. El personaje prototípico se construye a través de historias diferentes mediante roles que tienen en común unos elementos deseables para el gran público como belleza, misterio, atractivo, fortaleza, ternura, ingenuidad... Las cualidades del personaje se atribuyen al actor y la personalidad pública del actor se proyecta sobre los personajes: el resultado de esta interrelación es la estrella, que posee un glamour, un aura que la sitúa por encima de los mortales, en el espacio preciso que ocupa el héroe en la mitología griega (entre los dioses y los humanos)".

Si las estrellas interesan en este estudio es por su capacidad por atraer al público y generar beneficios. En la actualidad, los espectadores van al cine para ver "la película de...". Interesan los nombres de las estrellas, quién protagoniza cada cinta. Los carteles nos venden grandes elencos o castings estelares. Julia Roberts, Antonio Banderas, Catherine Zeta Jones, Brad Pitt, George Clooney... El cine es asunto de nombres propios y los actores suelen estar por encima del director. Los estudios lo saben y si hay varias estrellas en la misma película, el éxito está casi asegurado.

Esta costumbre actual ha sido heredada del primer Hollywood, que inventó el star system. Los grandes estudios se dieron cuenta de que las estrellas, por sí solas, podían atraer al público sólo con aparecer en cartel. Las productoras se subordinaron a ellas y como explica Sánchez Noriega (2006, p. 219): “El sistema de estudios (studio-system) se convierte en sistema de estrella (star-system): el guión y el director, además de la temática, la ambientación y el vestuario están subordinados a la estrella". La nueva industria había encontrado un método fácil y seguro para vender 
sus películas, "pero no se puso en marcha de la noche a la mañana. Se desarrolló como un eslabón de un complejo sistema de principios industriales" (Gomery et al, 1998, p. 86).

Lo cierto es que el teatro de la época ya utilizaba un sistema de estrellas parecido. Los grandes actores trabajaban en una obra detrás de otra y les contrataban por su capacidad para llenar el patio de butacas. Sus sueldos no eran tan elevados, pero sus nombres tenían precio. De hecho, muchos actores de cine procedían de las tablas teatrales. El cine encontró a sus primeras estrellas sobre los escenarios tradicionales y para seleccionarles, se les obligaba a leer algún pasaje teatral, llamado playlet:

“Una versión breve y resumida de una célebre novela u obra teatral, en la que unos actores daban vida a famosos personajes conocidos del público. Así fue como comenzó la demanda de estrellas. Las nuevas compañias cinematográficas empezaron a contratar estrellas del teatro y del vodevil. Pero se les agotaron pronto los argumentos extraídos de las obras antiguas y famosas $y$, en consecuencia, empezaron a contratar a autores de narraciones populares, que solían trabajar para los periódicos sensacionalistas, para que convirtieran situaciones contemporáneas en historias interesantes susceptibles de ser filmadas con las estrellas que tenían contratadas" (Gomery et al, 1998, p. 88).

Poco a poco, algunos actores abandonaban el teatro definitivamente. El cine era un negocio mucho más rentable, requería menos esfuerzos, y generaba mayores sueldos. Los estudios querían tener contentos a sus artistas. Les ofrecían contratos millonarios y en exclusiva, para que no pudieran trabajar a la vez para varios estudios. Esos contratos se hacían por meses e incluso, por años. La estrella encadenaba una película con otra y si no había proyecto, se quedaban sin rodar nada pero seguían percibiendo su sueldo. 
Era un trabajo más mecánico y menos artístico. Retiraban a grandes actores de los escenarios y algunos no tenían la misma calidad en la gran pantalla, o dejaban al público sin la posibilidad de disfrutarles en vivo. Además, surge otra vez el aspecto del arte ambulante. Las compañías de teatro viajaban por todo el país. Después de cada actuación, volvían a la carretera y la labor resultaba extenuante para el actor. En cambio, Hollywood ofrecía una gran ventaja: el trabajo dejaba de ser ambulante, ya que todas las películas se rodaban en Hollywood, en un perímetro de pocos kilómetros. Esta tranquilidad era razón suficiente para convencer a muchas estrellas del teatro: más comodidad y más salario. El estudio ganaba un actor de calidad y se aseguraba una cantidad ingente de dinero. Muy pronto, "la identificación inmediata de los personajes por el público era el medio del que se valía el star system de Hollywood para vender las nuevas películas" (Gomery et al, 1998, p. 94). Se puede decir que las estrellas son creaciones de la industria y del público. También explican:

"El productor elige a un actor o actriz con el suficiente carisma y fabrica una estrella mediante películas pensadas para su lucimiento y para la construcción de un prototipo, los reportajes de prensa que difunden determinados comportamientos u opiniones, la fabricación de una biografía con elementos de misterio o exóticos, una vida de lujo, etc. Así, Theodosia Goodman, hija de un sastre de Cincinnati, fue transformada en Theda Bara, una actriz que había nacido en Egipto, de orígenes reales, fue amamantada con sangre de serpiente, para ser entregada como esposa virgen a la Esfinge; poco después fue raptada por las tribus nómadas del desierto, se transmutó en una mujer fatal e imposible, capaz de hipnotizar y atolondrar a todos sus amantes" (Sánchez Noriega, 2006, p. 219).

Los estudios demuestran que hacia 1911, el público ya conocía bien a sus estrellas. Se elaboraban encuestas para ver qué actores eran los favoritos del público. Fue entonces cuando los carteles, programas y fotografías publicitarias empezaron a ser 
colgados en las paredes y fachadas de los cines. Por si fuera poco, "estas fotografías aparecían en ocasiones coloreadas" (Gomery et al, 1998, p. 106), mientras que el cine aún tardaría mucho en abandonar el blanco y negro. El objetivo era simple: "Había que hacer de cada nueva película un producto especial que se vendiera por sí mismo" (Gomery et al, 1998, p. 58).

Aunque el trabajo en el cine parecía sencillo y más llevadero que el teatral, para algunas estrellas también resultó ser extenuante:

"El tiempo era esencial, así que los actores pasaban rápidamente de una película a otra. Se solían emplear varias cámaras en el rodaje de las escenas complicadas, como por ejemplo las batallas, para no tener que rodarlas dos veces. Y siempre estaba presente la secretaria de rodaje, que se ocupaba de que las distintas partes de la película, que se rodaban de forma desordenada, pudieran montarse fácilmente" (Gomery et al, 1998, p. 64).

Toda esta megalomanía y cinefilia llevó al nacimiento de otra industria nueva, el de las revistas para cinéfilos. En España leemos Fotogramas, Cinemanía o Dirigido por. Sin embargo, a principios del siglo XIX, ya existían revistas parecidas, con menos fotografías a color pero con el mismo, o mayor, número de lectores:

"Una de ellas fue el Moving Picture Story Magazine, publicación fundada por J. Stuart Blackton, de la compañía Vitagraph, en colaboración con otros miembros de la Motion Patents Company. Estas revistas se centraban en las nuevas estrellas y publicaban artículos sobre sus películas, ilustrados con imágenes de los films y fotografías publicitarias. Las revistas para cinéfilos no tardaron en incluir en sus páginas una sección en la que los aficionados al cine podían requerir información sobre sus estrellas favoritas, y solicitar fotografias y tarjetas postales filmadas" (Gomery et al, 1998, p. 113). 
Por todo lo indicado anteriormente, el star system es un ejemplo más de la industrialización del arte que genera beneficios, rentabilidad y remite a la siguiente cita: "La reproducción, premiación, mercabilización y jerarquización del saber y la cultura no se restringen, en el doctor Franklin, a crear círculos de eruditos y especialistas que se elogian entre sí y se unen para defender sus experimentos e invenciones según premisas de rentabilidad" (Orozco, 2002, p. 61). Efectivamente, el objetivo no es generar conocimiento, sino dinero; de ahí el nombre de "industria del cine".

\section{El resultado: la película, ¿producto u obra de arte?}

Después de haber analizado todo el proceso de producción y creación, llega el producto final: la película, base de la industria de Hollywood, vehículo principal para llegar al público y ganar dinero con las entradas de cine. Sin embargo, el corporativismo y el sistema económico e industrial que hay en cada etapa llevan a preguntarse qué porcentajes de arte y producción en serie tiene el filme. ¿Hasta qué punto una película es creación artística? ¿Predomina el factor económico y las películas apenas se diferencian entre sí?

Dadek (1962, p. 22), en su manual sobre Economía Cinematográfica, intenta dar algunas claves:

"Frecuentemente se califica a la película como un producto masivo, queriendo significar con ello que, como muchos otros productos, es obra de un proceso de producción estandarizado. Ciertas apariencias externas como la circunstancia, entre otras, de ser producida por una industria, o el hecho de que su compensación económica se logre por los cientos de miles de pequeños ingresos en las taquillas de los cines - inducen a esta apreciación. Pero se trata de un gran error basado en un análisis insuficiente $y$, en parte 
también, en el desconocimiento de la significación exacta del concepto de producción en masa".

Cuevas (1999, pp. 45-46), autor del otro manual sobre economía en el Séptimo Arte, utiliza términos e ideas semejantes y define la película como un prototipo:

\begin{abstract}
“Cada película es un prototipo. Un modelo. Sólo es posible la fabricación en serie en la multiplicación de copias de cada uno de estos modelos o prototipos. Y la consecución de cada unidad de obra supone tal inversión de trabajo, tiempo y capitales que los errores resultan decisivos".
\end{abstract}

La decisión, como siempre, está en mano del público. Éste decide qué película es puramente arte y cuál es meramente industria. Si le interesa, se dejará llevar para asistir a un gran estreno, una película de aventuras o de acción, que se parece misteriosamente a las últimas que trataron el mismo tema. Si prefiere el arte, tendrá que esperar alguna semana más para ver una obra de arte, ya que ésas no se fabrican en serie.

\title{
8. De ayer a hoy. La historia siempre se repite.
}

Segrave (en Buquet, 2005, p. 116) resume en las siguientes líneas los primeros años de expansión de Hollywood hacia el mundo exterior:

"A principios de siglo, con el inicio de la industrialización del cine, los mercados exteriores pasaron a formar parte esencial de la rentabilidad de las películas. Ya en 1917, una carta anónima en Bioscope expone que los mercados exteriores deberían asumir los nuevos altos costes del cine americano. En aquella fecha, la escalada en los costes medios de las películas había crecido tanto, que los mercados extranjeros eran esenciales para 
amortizar las producciones de Hollywood. Algunos datos concretos confirmarían esta ofensiva por el cine norteamericano en la segunda década del siglo XX, a saber: en Australia, previo a 1914 no se conocía el cine norteamericano, y en 1920, EE.UU. ocupaba el 95\% de ese mercado; en 1917, el cine de EE.UU. ocupaba el 90\% del mercado en Reino Unido; y, por último, la cuota del cine francés en época similar había bajado del 80 al 30,4\% al interior de su mercado".

Los datos hablan por sí solos. Hollywood creció rápidamente en California y Estados Unidos, y aún con celeridad en el resto del mundo. España también vivió su expansión y en la actualidad, el Gobierno intenta crear una Ley de Cuota de Pantalla para fomentar las películas españolas y europeas por encima de las norteamericanas. Parece algo imposible, porque ninguna película española ha superado los dos millones de euros de recaudación, cifra que es mínima como presupuesto para una película americana. El gigante norteamericano sigue creciendo, en cine y en televisión. Los estudios son cada vez más grandes, hacen películas más variadas e inventan series de televisión que se venden en DVD más que muchas películas.

Por si eso no fuera suficiente, cuando es necesario, las productoras se alían y aúnan esfuerzos, o absorben a productoras independientes que han cosechado algún éxito discreto:

"La tendencia hacia la gran empresa - en la producción y en la distribución, pero sobre todo en la primera - y la concentración vertical - por propio desarrollo de las empresas cinematográficas (como, por ejemplo, la creación por una productora de su propia organización distribuidora), pero, principalmente, a través de la unión de firmas productoras y distribuidoras anteriormente independientes - van siempre de la mano y son la fibra del movimiento concentrador" (Dadek, 1962, p. 205). 
Es la política de la "joint-stock-society, el de la sociedad por acciones y sus jerarquías y espacios participatorios" (Orozco, 2003, p. 35). El sistema de estudios sigue utilizando la parcelación del trabajo. Cada uno conoce las acciones que ha de desarrollar, cuál es su espacio de trabajo y su cometido; en definitiva, el pragmatismo absoluto. Mantienen la antigua política de Hollywood y hacen el trabajo moderno desde lo que inventaron en la creación de la meca del cine. El cine avanza, mejoran los efectos especiales, la animación supera la realidad pero los objetivos de rentabilidad siguen siendo los mismos: "La divisa de custodiar lo moderno desde el mirador privilegiado de la antigüedad y la premodernidad incrementa la sagacidad para vérselas con la inmensa paradoja de la revolución informática y el renacimiento de los fundamentalismos que paraliza ya al pragmatismo" (Orozco, 2004, p. 302).

\section{Conclusiones.}

La creación de Hollywood es buen ejemplo para conocer el corporativismo norteamericano, que sigue vigente hoy en día. La meca del cine nació en el Oeste para luchar contra el Trust del Este; huía de una concentración monopólica para crear otra concentración más libre llamada sistema de estudios.

En la actualidad, su trabajo se define con datos muy claros:

- “En EE.UU. se producen anualmente más de 600 películas. Las cien primeras acumulan alrededor del $70 \%$ de la recaudación en taquilla. En el extremo opuesto encontramos 250 películas que no logran ser estrenadas. Pues bien, de todas las películas que se producen anualmente en EE.UU., sólo 200 títulos, los que han sido avalados por el éxito en el mercado doméstico, se exportan y compiten con las películas europeas" (Buquet, 2005, p. 23).

- "El mercado conjunto europeo y norteamericano, formado por miles de empresas productoras y distribuidoras, está dominado por seis grandes corporaciones 
norteamericanas que producen y distribuyen obras cinematográficas: Warner, Disney, Sony, Universal, Fox y Paramount. Estos seis gigantes empresariales concentran más del 90\% del mercado" (Buquet, 2005, p. 23).

- "Los recursos generados por la industria audiovisual de EE.UU. representan aproximadamente el doble de los generados por la industria audiovisual de la UE; esta notable diferencia en la capacidad financiera genera ya de por sí una enorme ventaja competitiva para la industria de programas de ficción de EE.UU. sobre la UE" (Buquet, 2005, p. 67).

El resultado son cifras millonarias. Las películas cuestan, como media, 100 millones de euros, y pueden recaudar 700 sólo en el primer fin de semana. Después, llega el merchandising, la promoción mundial, los videojuegos, el lanzamiento en DVD y su venta en la televisión. Se puede decir que los estudios nos engañan; nos venden películas muy similares, con argumentos muy parecidos y se defienden afirmando que dan "lo que el público quiere ver". A pesar de ello, hay que reconocerles sus éxitos: están pegados a la realidad, buscan tecnología nueva cada día, se arriesgan con algunos productos de calidad y como en todo arte, hay ejemplares irrepetibles que surgen cada cierto tiempo. El público debe quedarse con esas obras de arte, distintas e irrepetibles. Pero no hay que denostar las grandes superproducciones, ya que son fruto de una política y una forma de trabajo que podrían inspirar a otras industrias.

Lo bueno es que el espectador tiene la capacidad y libertad de decidir. No hay un monopolio obligatorio, ni un producto único. El pragmatismo y el corporativismo han dejado espacio para cierta variedad. Las películas minoritarias son pocas, pero existen y Hollywood las reconoce. Por ello se puede decir que "la vida humana más profunda está dondequiera, y es eterna" (Orozco, 2003, p. 99) y el hombre puede encontrarse a sí mismo en una gran película de dos horas y media y elevado 
presupuesto, o en una modesta cinta de noventa minutos, rodada con unos pocos miles de dólares.

\section{Bibliografía.}

BUQUET, G. (2005): El poder de Hollywood. Datautor. Madrid.

CUEVAS, A. (1999): Economía Cinematográfica. La producción y el comercio de películas. Productores Audiovisuales Entidad de Gestión de Derechos. Madrid.

DADEK, W. (1962): Economía Cinematográfica. Rialp. Madrid

GOMERY, D., LEUTRAT, J.L. y MARZAL, J.J. (1998): Historia del Cine. Volumen II. EE.UU (1908-1915). Cátedra. Madrid.

GUBERN, R. (1997): Historia del Cine. Editorial Lumen. Barcelona.

OROZCO, J.L. (2002): Benjamín Franklin y la fundación de la república pragmática. Fondo de Cultura Económica. México D.F.

OROZCO, J.L. (2003): William James y la filosofía del siglo americano. Gedisa. Barcelona. OROZCO, J.L. (2004): El siglo del Pragmatismo Político. UNAM. México D.F., Fontamara.

SADOUL, G. (1998): Historia del cine mundial. Siglo Veintiuno Editores. Madrid.

SÁNCHEZ NORIEGA, J.L. (2006): Historia del cine. Teoría y géneros cinematográficos, fotografía y televisión. Alianza Editorial. Madrid. 